\title{
Meeting with Elected Officials ${ }^{1}$
}

\section{Ricky Telg and Shelli Rampold ${ }^{2}$}

This EDIS document is part of a series on communicating with policymakers and elected officials. The series includes the following EDIS documents:

\section{Speaking with Policymakers about Current Issues (http:// edis.ifas.ufl.edu/wc152)}

2. Communicating with Local Elected Officials (http://edis. ifas.ufl.edu/wc316)

\section{Strategies for Engaging and Communicating with Elected Officials (http://edis.ifas.ufl.edu/wc324)}

\section{Introduction}

A personal visit from a constituent makes an immediate impact and a long-lasting impression on elected officials. Knowing (a) how to prepare for a personal visit, (b) what to do during a visit, and (c) how to prepare informational materials are important aspects of creating this positive impact. As noted in the EDIS publication Communicating with Elected Officials, Florida's county commissioners most preferred for constituents to communicate information to them via face-to-face scheduled meetings or email. Phone or conference calls and written letters were moderately preferred. These findings may well hold true for state and national elected officials as well. But how do you conduct a face-to-face visit? This document provides suggestions on how to conduct an effective personal visit with elected officials, particularly at the state and federal levels. Please note that Extension faculty should receive administrative approval before conducting a formal visit to an elected official. As noted in the EDIS publication Communicating with Local Elected Officials, in the Extension setting, advocating is typically a special role for volunteers or advisory board members, and not a role of Extension faculty. Please refer to Communicating with Local Elected Officials for information about the distinction between advocating and educating.

\section{Preparing for the Visit}

- Schedule the visit. State and federal legislators can be in committee meetings or in their respective chambers (House or Senate). They may also see 10 to 15 individuals or groups per day through scheduled visits. Their time is limited, so plan ahead by scheduling the visit.

- Tell them what you want to discuss. When you schedule the visit, it is courtesy to inform the person setting up the appointment what it is you want to discuss.

- Prepare yourself that you may not see the elected official. As state and federal legislators are very busy, you may not be able to see them. You may instead see the legislator's staffer. Most staffers specialize in one or two content areas. They are extremely knowledgeable about particular topics, and a legislator often votes based on information his or her staffer has learned and conveyed. Staffers, therefore, are very important.

- Know all "sides" of the issue. If there is "another side" to an issue, know what the other side is. If the staffer or elected official asks about the opposing view, you will then be prepared to respond.

1. This document is AEC655, one of a series of the Department of Agricultural Education and Communication, UF/IFAS Extension. Original publication date January 2019. Visit the EDIS website at https://edis.ifas.ufl.edu for the currently supported version of this publication.

2. Ricky Telg, professor; and Shelli Rampold, research coordinator, Center for Public Issues Education in Agriculture and Natural Resources; UF/IFAS Extension, Gainesville, FL 32611.

The Institute of Food and Agricultural Sciences (IFAS) is an Equal Opportunity Institution authorized to provide research, educational information and other services only to individuals and institutions that function with non-discrimination with respect to race, creed, color, religion, age, disability, sex, sexual orientation, marital status, national origin, political opinions or affiliations. For more information on obtaining other UF/IFAS Extension publications, contact your county's UF/IFAS Extension office. 


\section{What to Do During a Visit}

- Keep it brief and simple. You may have more time with local elected officials (city council members, county commissioners) than state or federal elected officials. However, in all cases, understand that their time is valuable. When you arrive, quickly explain who you are and why you are visiting. At the state and federal levels, you may get 15 to 20 minutes with a staffer and then possibly another 15 minutes with an elected official. A visit longer than 30 minutes total is uncommon. Because visits are brief, you have to be ready to communicate your story and what it is you want.

- Technical knowledge. Make technical information concise and understandable. Do not overwhelm them. Use an infographic to help explain your point if necessary.

- Common ground. Find common ground with the elected official. Thank them if they have done something positive for your issue. Do not be partisan at all.

- Focus. Get to "the ask" quickly because visits are brief. "The ask" is what you want the elected official to do or what you want to inform the elected official about. For Extension, it is likely "the ask" will be made by a volunteer or advisory board member. Examples of an "ask" that would be done by a volunteer or advisory board member would be a request for funding. An Extension faculty member's "ask" could focus on explaining past programs' successes and indicating possible needs and trends for future successes.

- Provide informational materials and handouts. Be careful about the amount of print material. Big packets may never get read. Do not drown them in details and paper. Remember, you may be one of 10 groups on any given day who will also have handouts for the elected official.

- Multipage PDF documents. Similarly, as staff and elected officials use their cell phones for information gathering, it is best not to email multipage PDF documents. They cannot easily read a lot of information on a small screen. One-page documents are best, especially if emailed.

- Business cards. Bring a lot of business cards. You will hand out one, or sometimes many, at every visit.

- One-pager. Leave a one-page document ("one-pager") behind. The one-pager should have "the ask" at the top and very specific information in the document (Figures $1-2)$.

- Listen. Be a good listener. Do not feel that you have to fill time talking. Provide ample opportunities during your visit for the elected official to ask clarifying questions, and be ready to respond to the elected official's questions.

- Look for photo opportunities. Take a photo with the elected official and tweet it. Promote them on Twitter. They'll likely promote you.

- Know your role.

- Groups. If a delegation visits an elected official, each person must know who is taking the lead during the visit. Know each person's role. Also, keep the delegation relatively small, with preferably six or fewer people.

- Appointment scheduling. If your delegation plans to meet with many elected officials on the same day, space out the appointments (time-wise) so that there is less chance for missing an appointment if an earlier appointment runs long. Break up into smaller groups if appointments are tightly scheduled, so that you do not miss a scheduled meeting.

- Follow up. Get a business card from a staffer and follow up via an email with any information they requested.

\section{How to Prepare Informational Materials}

Informational materials, sometimes called "leave behinds," should be brief but clear. As noted previously, elected officials receive a lot of printed materials every day. Brief documents may be more likely read than multipage documents. Do not plan to leave behind USB drives, especially when meeting with federal officials. At the federal level, USB drives are confiscated and checked for security purposes, which may delay their use by an elected official for several weeks. The two most common informational materials for visits are one-pagers and letters or emails.

- One-pager. The one-pager should have "the ask" at the top and very specific information in the document. Sometimes a one-pager will be a front/back document, but that should be the maximum length of a "leave behind." Example one-pagers are provided here.

- Letter or email: Elected officials like to receive letters from constituents. However, at the federal level, letters sent in envelopes are processed and checked by security for threats such as anthrax. As such, an enveloped letter may take several weeks before it reaches a federal elected official. Emails are preferred, especially from individuals living in an elected official's district.

- Writing the letter or email. The letter or email should be clear and straightforward. Get to "the ask" in the first 
paragraph. Do not assume the elected official knows what you know. End with a "thank you." For more information on writing letters and emails, refer to the EDIS publication Business Communication.

- Writing a thank you note. Sending a formal "thank you" note or card after a meeting with elected officials is not necessary, but it is another way to get your name across the elected official's desk. Because of the volume of correspondence they receive, typically send a "thank you" as part of a follow-up if the elected official or a staff member requests more information from you.

\section{Summary}

This document provided suggestions related to visiting elected offiicals, particularly state and federal elected officials. By following these recommendations on how to prepare for a visit, what to expect in a visit, what to do during a visit, and how to prepare informational materials, you will be better able to have an effective visit with an elected official.

\section{Reference}

Telg, R. W. 2010. Business Communication. WC097. Gainesville: University of Florida Institute of Food and Agricultural Sciences. http://edis.ifas.ufl.edu/wc097 


\section{UF/IFAS Tropical Aquaculture Lab}

Sponsor: Representative James "J.W." Grant and Senator Dana Young

This funding request is to restore funds vetoed in the 2017-18 fiscal year. The UF/IFAS Tropical Aquaculture Laboratory (TAL), located in Ruskin, Florida, provides research, Extension programs, and Education focused on the state's unique tropical fish industry, TAL also addresses other critical issues to the state's diverse aquaculture industry. Florida leads the nation, providing $95 \%$ of ornamental fish.

What we do...Program focus areas include new species development, nonnative aquatic species management, aquatic animal disease diagnostics, restoration aquaculture, management of aquatic materials application, and general production management. The TAL, through Extension programs and research, has a long-term program designed to assist farms with training and testing for their applications, and labeling of new products. The restoration aquaculture programs are a joint partnership with the Florida Aquarium and FWC at the Center for Conservation in Apollo Beach which includes tenure track faculty, graduate students, and program support.

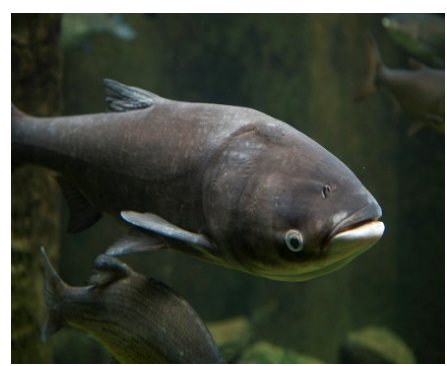

The full service diagnostic lab provides services to commercial farms, trains veterinary students, and issues health certificates required for Fish \& Wildlife Conservation stock enhancements. In 2016, one farm reported a savings of over $\$ 12$ million by using this service.

\section{TAL is the only resource for tropical fish farmers with sick fish... The TAL is the} only aquaculture lab in the nation dedicated to ornamental aquaculture and the only aquaculture lab in Florida with a full service disease diagnostic lab that provides treatment and prevention recommendations, trains students and conducts educational programs. Working closely with industry, state, and federal agencies, the TAL provides science-based information used to make management and regulatory decisions.

Return on Investment and additional sources of funding... The total non-state support for programs at the TAL is $\$ 3,559,000$ representing almost a 4.5:1 leveraging of state funds invested. Surveys of farms participating in various aspects of TAL programs continuously result in testimonials of how they have saved or generated

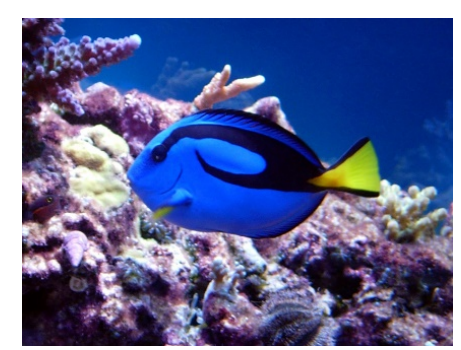
millions of dollars each year. A preliminary survey of clients has shown that in FY 2016 the direct economic impact of programs delivered by the TAL exceeded $\$ 13,000,000$ in increased profits and/or savings to commercial farms. For every $\$ 1$ of state funds invested, our clientele generated $\$ 16.68$ as a direct result of our programming.

What we've done... One example - in 2016, the TAL was the first in the world to successfully spawn, hatch, and rear the Pacific Blue Tang, made popular in the film Finding Dory. This opened the door for successful commercial rearing of the Blue Tang, reducing the impact on fish populations harvested from the wild, and providing Florida farms with an opportunity to secure part of a $\$ 2$ million/year market.

Invasive Species... Through its research and extension programs, the TAL has developed into a national leader in the science of invasion biology (development of unique tools to address invasive species such as lionfish, walking catfish, Asian carp, etc.).

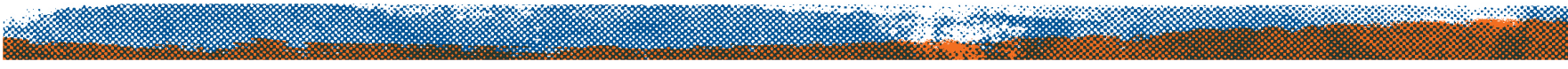

Figure 1. UF/IFAS Tropical Aquaculture Lab One-Pager.

Credit: IFAS Governmental Affairs 


\section{UF/IFAS Florida Horticulture, $\$ 1,450,000$ Research, Science \& Education

\section{Sponsor: Representative Matt Caldwell and Senator Denise Grimsley}

This request is to replace funding for the Florida Horticulture Research, Science \& Education that was previous vetoed in the 2017-2018 session. These funds provide the resources for the partnership between the UF/IFAS Center for Landscape Conservation and Ecology (CLCE) and the UF/IFAS Public Information and Education Center (PIE).

What we do... The (CLCE) undertakes integrated research projects that focus on the sciences such as horticulture, economics, water quantity and quality. It develops and promotes research-based best management practices among landscape professionals and other members of the agricultural industry. In addition to water conservation, CLCE research results in reduced use of pesticides, insecticides, fertilizer and other chemicals that can leech into our water sources.

In partnership with the PIE center, the public/stakeholder groups are provided with the information and technology developed at the CLCE. The purpose is to increase implementation of new techniques, practices and technology and how to effectively manage landscapes while adhering to conservation practices.

\section{Florida's nursery and landscape industry accounts for 232,000 plus jobs and}

$\$ 21.08$ billion in overall total output sales in the state's economy out of the $\$ 120$ billion agricultural industry. Industry output has increased $37 \%$ between 2010 and 2015 in part due to the science and extension education provided by CLCE. The CLCE's FloridaFriendly Landscaping ${ }^{\mathrm{TM}}$ program has served as a model for several other urban landscape programs in Louisiana, North Carolina, Tennessee, and South Carolina.

What we've done....In 2016, over 265 million gallons of water were saved in Florida through a direct impact from the center's major extension programs. This is enough water to supply the annual indoor water needs of nearly 3,000 homes. The cumulative impact is 250,000 each successive year.

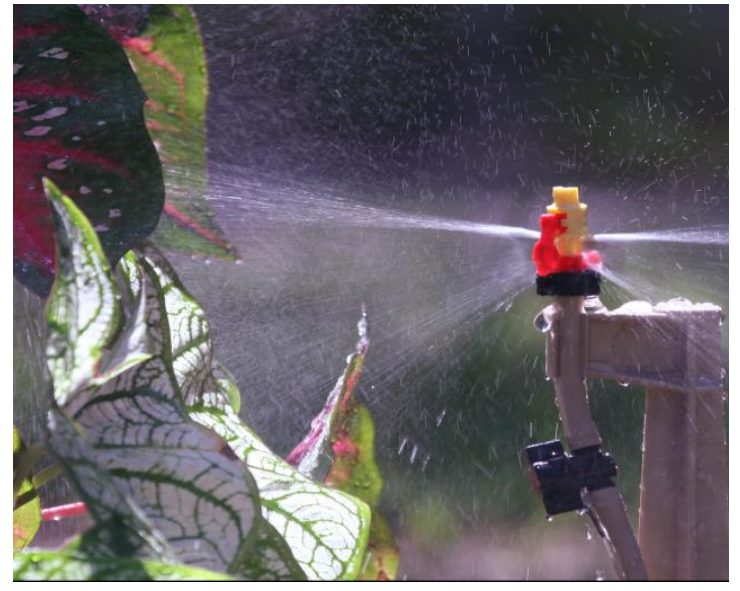

Figure 2. UF/IFAS Florida Horticulture, Research, Science \& Education One-Pager.

Credit: IFAS Governmental Affairs 